\title{
New Cyclopentenone Derivatives from an Endophytic Streptomyces sp. Isolated from the Mangrove Plant Aegiceras comiculatum
}

\author{
Wenhan Lin, Liya Li, Hongzheng Fu, Isabel Sattler, Xueshi Huang, Susanne Grabley
}

Received: July 11, 2005 / Accepted: September 6, 2005

(C) Japan Antibiotics Research Association

\begin{abstract}
From the mangrove plant Aegiceras comiculatum collected in South China an endophytic Streptomyces sp. was isolated. Following cultivation in a seawater-based medium, four new cyclopentenone derivatives, namely $(5 R)$ 3-amino-5-hydroxy-5-vinyl-2cyclopenten-1-one (1), (5R) 5-hydroxy-3-[(methoxycarbonyl)amino]-5-vinyl-2-cyclopenten-1-one (2), (5R) 5hydroxy-3-[[2-(4-hydroxyphenyl)ethyl]amino]-5-vinyl-2cyclopenten-1-one (3), and 3-isobutylpropanamide-2cyclopenten-1-one (4), were obtained from the fermentation broth. Their structures were elucidated by extensive spectroscopic (UV, IR, ESIMS, and 2D NMR) data analyses.
\end{abstract}

Keywords endophyte, Streptomyces sp., Aegiceras comiculatum, (5R) 3-amino-5-hydroxy-5-vinyl-2-cyclopenten-1-one, cyclopentenone derivatives

\section{Introduction}

Endophytes are microorganisms that invade the healthy tissues of living plants without causing disease symptoms. The endophytic association with the hosts results in advantages, such as increased plant growth, deterrence of fungal pathogens, prevention of herbivory, and drought tolerance. Endophytic microorganisms from mangrove plants have become an important source of pharmacologically active metabolites $[1 \sim 7]$. In continuation of our investigation on chemical diversity from marine microorganisms, an endophytic Streptomyces sp. was isolated from the mangrove plant Aegiceras comiculatum, which has been examined chemically [8]. From the cultivation in a seawater-based medium, four new cyclopentenone derivatives $(\mathbf{1} \sim \mathbf{4})$ were isolated. This paper reports a structure elucidation of the obtained compounds.

\section{Results and Discussion}

Compound 1 was isolated as a yellowish oil, and its molecular formula was established as $\mathrm{C}_{7} \mathrm{H}_{9} \mathrm{NO}_{2}$ on the basis of HRESIMS data $\left(\mathrm{m} / z 162.0540[\mathrm{M}+\mathrm{Na}]^{+}\right.$, calcd. 162.0531) and NMR data, indicating four degrees of unsaturation. The IR absorptions at 3308, 3181, 1617, and $1531 \mathrm{~cm}^{-1}$ suggested the presence of hydroxyl or/and amino, and olefinic groups. The ${ }^{1} \mathrm{H}$ NMR spectrum exhibited the signals for a mono-substituted vinyl group at $\delta_{\mathrm{H}} 5.15(1 \mathrm{H}, \mathrm{dd}, J=1.2,10.5 \mathrm{~Hz}), 5.37(1 \mathrm{H}, \mathrm{dd}, J=1.2$, $17.1 \mathrm{~Hz})$, and $5.89(1 \mathrm{H}, \mathrm{dd}, J=10.5,17.1 \mathrm{~Hz})$, a trisubstituted vinyl proton at $\delta_{\mathrm{H}} 4.98(1 \mathrm{H}, \mathrm{brs})$, and aliphatic methylene signals at $\delta_{\mathrm{H}} 2.85(1 \mathrm{H}, \mathrm{d}, J=17.4 \mathrm{~Hz})$ and 2.70 $(1 \mathrm{H}, \mathrm{d}, J=17.4 \mathrm{~Hz})$. The ${ }^{13} \mathrm{C}$ NMR and DEPT spectra displayed seven carbon signals involving a keto carbon at $\delta_{\mathrm{C}} 204.67(\mathrm{~s}, \mathrm{C}-1)$, four olefinic carbons at $\delta_{\mathrm{C}} 114.2$ (t, C7), 141.2 (d, C-6), 179.2 (s, C-3), and 97.8 (d, C-2), one oxygenated quaternary carbon at $\delta_{\mathrm{C}} 80.0(\mathrm{~s}, \mathrm{C}-5)$, and a methylene at $\delta 44.2$ (t, C-4). The HMQC spectrum
W. Lin (Corresponding author), L. Li, H. Fu: State Key Laboratories of Natural and Biomimetic Drugs, Beijing, 100083, P. R. China, E-mail: whlin@bjmu.edu.cn
I. Sattler, X. Huang, S. Grabley: Hans-Knoell-Institute for Natural Products Research, Beutenbergstr. 11a, D-07745 Jena, Germany 
supported the assignment of the chemical shifts for the protonated carbons. The above NMR data were very similar with those reported for 3-dimethylamino-5-hydroxy-5vinyl-2-cyclopenten-1-one [9], in which the carbon signals of $\beta$-dimethylamino substituted propenone unit were assigned to 200.9 (s), 174.1 (s), and 96.1 (d), respectively [9]. The HMBC and COSY correlations of $\mathbf{1}$ further supported the existence of a cyclopenten-1-one unit. The HMBC correlations from the vinyl methylene protons at $\delta_{\mathrm{H}}$ 5.15 (dd) and 5.37 (dd) to C-5, and from $\delta_{\mathrm{H}} 5.89$ (dd) to C$4, \mathrm{C}-5$, and $\mathrm{C}-1$, deduced the location of the terminal double bond and a hydroxyl group at the same position C5 , and confirmed the partial structure of 5-hydroxy-5-vinyl2-cyclopenten-1-one. The remaining elements of $\mathrm{NH}_{2}$ was obviously consistent with an amino group which was linked to $\mathrm{C}-3$ rather than to $\mathrm{C}-2$ of the cyclopenten-1-one. This fact was deduced by the singlet olefinic proton at $\delta_{\mathrm{H}} 4.98$ $(1 \mathrm{H}$, br s, H-2) showing no NOE correlation with the methylene protons at $\mathrm{C}-4$ and the vinyl signal C-3 $\left(\delta_{\mathrm{C}}\right.$ 179.2, s) resonated at extremely downfield. In regard to the stereochemistry of chiral carbon C-5, the value of optical rotation $\left([\alpha]_{\mathrm{D}}+127.1^{\circ}\right)$ mainly induced by the substituents at $\mathrm{C}-5$ was in positive, the same phase as that of 3methoxy-5-hydroxy-5-vinyl-2-cyclopenten-1-one $\quad\left([\alpha]_{\mathrm{D}}\right.$ $+63^{\circ}$ ) [11], implying that both compounds shared the same configuration. Since the CD spectrum of latter showed a positive Cotton effect at $281 \mathrm{~nm}\left(n \rightarrow \pi^{*}\right.$ transition) [10], analysis of the geometrical arrangement of the molecule in the eight octants formed by the symmetry planes of the orbital of the keto group indicated the absolute configuration as $5 R$. Accordingly, the configuration of C-5 in $\mathbf{1}$ was supposed to be $5 R$. The structure of $\mathbf{1}$ was thus determined as (5R) 3-amino-5-hydroxy-5-vinyl-2cyclopenten-1-one.

The molecular formula of $\mathbf{2}$ was established as $\mathrm{C}_{9} \mathrm{H}_{11} \mathrm{NO}_{4}$ on the basis of HRESIMS ( $\mathrm{m} / \mathrm{z} 220.0590$, calcd. for $\left.\mathrm{C}_{9} \mathrm{H}_{11} \mathrm{NO}_{4} \mathrm{Na}, 220.0586\right)$ and NMR data, indicating a $\mathrm{C}_{2} \mathrm{H}_{2} \mathrm{O}_{2}$ unit more than that of $\mathbf{1}$. The comparable NMR spectral data between $\mathbf{1}$ and $\mathbf{2}$ indicated that $\mathbf{2}$ possessed the same basic skeleton of 5-hydroxy-5-vinyl-2-cyclopenten-1one. However, The NMR data of $\mathbf{2}$ differed from those of $\mathbf{1}$ in the substituent at $\mathrm{C}-3$ where presence of an additional methoxy group $\left(\delta_{\mathrm{H}} 3.78, \delta_{\mathrm{C}} 53.5\right)$ and a quaternary carbon $\left(\delta_{\mathrm{C}} 154.8, \mathrm{~s}, \mathrm{C}-1^{\prime}\right)$ were determined to form a methylcarbamate on the basis of the HMBC correlation between the methoxy protons and $\mathrm{C}-1^{\prime}$ in association with the evidence of the significant highfield value of the carbonyl carbon, a similar resonance as the same group in romucosine [11]. The stereo-configuration at C-5 was supposed to be the same as that of $\mathbf{1}$ due to the positive value of optical rotation of $\mathbf{2}$. The structure of $\mathbf{2}$ was thus determined as (5R) 5-hydroxy-3-[(methoxycarbonyl)amino]-5-vinyl-2-cyclopenten-1-one.

The HRESIMS and NMR data of 3 indicated its molecular formula to be $\mathrm{C}_{15} \mathrm{H}_{17} \mathrm{NO}_{3}$. Comparison of the ${ }^{1} \mathrm{H}$ and ${ }^{13} \mathrm{C}$ NMR data of $\mathbf{3}$ with those of $\mathbf{1}$ and $\mathbf{2}$ (Table 1) revealed a 5-hydroxy-5-vinyl-2-cyclopenten-1-one moiety, the same unit as that of $\mathbf{1}$ and $\mathbf{2}$. However, the NMR spectra indicated that $\mathbf{3}$ contained an additional $p$ hydroxyphenylethyl moiety from the signals at $\delta_{\mathrm{H}} 7.01$ $(2 \mathrm{H}, \mathrm{d}, J=8.5 \mathrm{~Hz}), 6.70(2 \mathrm{H}, \mathrm{d}, J=8.5 \mathrm{~Hz}), 3.42(2 \mathrm{H}, \mathrm{t}$, $J=7.2 \mathrm{~Hz})$, and $2.81(2 \mathrm{H}, \mathrm{t}, J=7.2 \mathrm{~Hz})$, and the carbon signals at $\delta_{\mathrm{C}} 157.2(\mathrm{~s}), 130.8(\mathrm{~d}, 2 \times \mathrm{C}), 116.4(\mathrm{~d}, 2 \times \mathrm{C})$, $47.2(\mathrm{t})$, and $34.9(\mathrm{t})$. This moiety was further confirmed by HMBC and COSY correlations, and it was deduced to form a $p$-hydroxyphenylethylamine at $\mathrm{C}-3$ of the cyclopentenone core on the basis of the HMBC correlation of the methylene protons at $\delta_{\mathrm{H}} 3.40(2 \mathrm{H}, \mathrm{t}, J=7.2 \mathrm{~Hz})$ with a carbon at $\delta_{\mathrm{C}} 176.2(\mathrm{~s}, \mathrm{C}-3)$. The stereochemistry of $\mathbf{3}$ was regarded to be the same as that of $\mathbf{1}$ and $\mathbf{2}$ due to the positive optical rotation. Therefore, the structure of $\mathbf{3}$ was determined as 5-hydroxy-3-[[2-(4-hydroxyphenyl)ethyl]amino]-5-vinyl-2-cyclopenten-1-one.

Compound 4 was isolated as white amorphous powder, the molecular formula of 4 was established as $\mathrm{C}_{12} \mathrm{H}_{19} \mathrm{NO}_{2}$ on the basis of HRESIMS and NMR data. The ${ }^{13} \mathrm{C}$ NMR and DEPT spectra of 4 displayed 12 carbon signals including two overlapping methyl resonances at $\delta_{\mathrm{C}} 20.1$ $(\mathrm{q})$, five methylene at $\delta_{\mathrm{C}} 47.0(\mathrm{t}), 35.3(\mathrm{t}), 33.7(\mathrm{t}), 31.8(\mathrm{t})$, and $28.9(\mathrm{t})$, one $s p^{3}$ methine at $\delta_{\mathrm{C}} 28.5(\mathrm{~d})$, one olefinic methine at $\delta_{\mathrm{C}} 129.3(\mathrm{~d})$, and three quaternary carbons at $\delta_{\mathrm{C}}$ 209.6 (s), 181.2 (s), and 170.9 (s). Analyses of ${ }^{1} \mathrm{H}$ and ${ }^{13} \mathrm{C}$ NMR data in association with 2D NMR correlations and comparison of its NMR data with those of $\mathbf{1}$ to $\mathbf{3}$ resulted in a basic skeleton of a cyclopentenone nucleus, in which the HMBC correlations between the methylene protons at $\delta_{\mathrm{H}}$ $2.38\left(\mathrm{~m}, \mathrm{H}_{2}-5\right)$ and the carbons at $\delta_{\mathrm{C}} 209.6(\mathrm{~s}, \mathrm{C}-1), 129.3$ (d, C-2) and 181.2 (s, C-3), and between the other methylene protons at $\delta_{\mathrm{H}} 2.58\left(\mathrm{~m}, \mathrm{H}_{2}-4\right)$ and $\mathrm{C}-1, \mathrm{C}-2$, and $\mathrm{C}-3$, as well as COSY correlation between $\mathrm{H}_{2}-4$ and $\mathrm{H}_{2}-5$ were observed. Moreover, a propionyl unit was established due to the COSY correlation between $\delta_{\mathrm{H}} 2.45(\mathrm{t}, J=7.2$, $\mathrm{H}_{2}-7$ ) and 2.75 ( $\mathrm{t}, J=7.2, \mathrm{H}_{2}-6$ ), and the $\mathrm{HMBC}$ correlations from H-6 and H-7 to a carbonyl carbon at $\delta_{\mathrm{C}}$ 170.9 (s, C-8). This moiety was deduced to link to C-3 through $\mathrm{C}-\mathrm{C}$ bond according to the $\mathrm{HMBC}$ correlations of $\mathrm{H}-2\left(\delta_{\mathrm{H}} 5.91, \mathrm{~s}\right)$ and $\mathrm{H}_{2}-4\left(\delta_{\mathrm{H}} 2.58, \mathrm{~m}\right)$ with a methylene carbon at $\delta_{\mathrm{C}} 28.9(\mathrm{t}, \mathrm{C}-6)$. The remaining four carbons were in constitute with a isobutyl group due to COSY correlations from $\delta_{\mathrm{H}} 1.76\left(\mathrm{~m}, \mathrm{H}-2^{\prime}\right)$ to $\delta_{\mathrm{H}} 3.07(\mathrm{dd}, J=6.3$, $\left.6.6 \mathrm{~Hz}, \mathrm{H}_{2}-1^{\prime}\right)$ and overlapping methyl protons at $\delta_{\mathrm{H}} 0.90$ (d, $J=6.6 \mathrm{~Hz}, \mathrm{H}_{3}-3^{\prime}, \mathrm{H}_{3}-4^{\prime}$ ), and the HMBC corrections 
Table 1 The ${ }^{1} \mathrm{H}$ and ${ }^{13} \mathrm{C}$ NMR data of compounds $\mathbf{1}$ to $\mathbf{4}$

\begin{tabular}{|c|c|c|c|c|c|c|c|c|}
\hline & \multicolumn{2}{|r|}{$1^{\mathrm{a}}$} & \multicolumn{2}{|r|}{$2^{\mathrm{a}}$} & \multicolumn{2}{|r|}{$3^{a}$} & \multicolumn{2}{|r|}{$4^{b}$} \\
\hline & $\delta_{\mathrm{C}}$ & $\delta_{\mathrm{H}}$ & $\delta_{\mathrm{C}}$ & $\delta_{\mathrm{H}}$ & $\delta_{\mathrm{C}}$ & $\delta_{\mathrm{H}}$ & $\delta_{\mathrm{C}}$ & $\delta_{\mathrm{H}}$ \\
\hline 1 & 204.7, s & & $207.8, s$ & & $204.1, \mathrm{~s}$ & & 209.6, s & \\
\hline 2 & $97.8, d$ & $4.98 \mathrm{brs}$ & 108.2, d & $6.03 \mathrm{brs}$ & $95.3, d$ & 4.93 br s & 129.3, d & $5.91 \mathrm{~s}$ \\
\hline 3 & 179.2, s & & 169.6, s & & 176.2, s & & 181.2, s & \\
\hline \multirow[t]{2}{*}{4} & $44.2, \mathrm{t}$ & $2.70 d(17.4)$ & $44.6, \mathrm{t}$ & $3.01 \mathrm{~d}(18.0)$ & $44.2, \mathrm{t}$ & $2.67 d(17.1)$ & $31.8, \mathrm{t}$ & $2.58 \mathrm{~m}$ \\
\hline & & $2.85 d(17.4)$ & & $2.84 \mathrm{~d}(18.0)$ & & $2.78 d(17.1)$ & & \\
\hline 5 & $80.0, \mathrm{~s}$ & & $78.3, \mathrm{~s}$ & & $79.4, \mathrm{~s}$ & & $35.3, t$ & $2.38 \mathrm{~m}$ \\
\hline 6 & 141.2, d & $5.89 \mathrm{dd}(10.5,17.1)$ & 140.0, d & $5.88 \mathrm{dd}(10.5,17.1)$ & 141.2, d & $5.85 \mathrm{dd}(10.8,17.1)$ & $28.9, \mathrm{t}$ & $2.75 \mathrm{t}(7.2)$ \\
\hline \multirow[t]{2}{*}{7} & $114.2, \mathrm{t}$ & $5.15 \mathrm{dd}(1.2,10.5)$ & $114.9, \mathrm{t}$ & $5.19 \mathrm{dd}(1.2,10.5)$ & $114.2, \mathrm{t}$ & $5.14 \mathrm{dd}(0.9,10.8)$ & $33.7, \mathrm{t}$ & $2.45 t(7.2)$ \\
\hline & & $5.37 \mathrm{dd}(1.2,17.1)$ & & $5.39 \mathrm{dd}(1.2,17.1)$ & & $5.34 \mathrm{dd}(0.9,10.8)$ & & \\
\hline 8 & & & & & & & 170.9, d & \\
\hline $1^{\prime}$ & & & $154.8, s$ & & $47.2, \mathrm{t}$ & $3.42 \mathrm{t}(7.2)$ & $47.0, \mathrm{t}$ & $3.07 \mathrm{dd}(6.3,6.6)$ \\
\hline $2^{\prime}$ & & & $53.5, q$ & $3.78 \mathrm{~s}$ & $34.9, \mathrm{t}$ & $2.81 \mathrm{t}(7.2)$ & $28.5, d$ & $1.76 \mathrm{~m}$ \\
\hline $3^{\prime}$ & & & & & 130.6, s & & $20.1, q$ & $0.90 \mathrm{~d}(6.6)$ \\
\hline $4^{\prime}$ & & & & & $130.8, d$ & $7.01 \mathrm{~d}(8.5)$ & $20.1, q$ & $0.90 \mathrm{~d}(6.6)$ \\
\hline $5^{\prime}$ & & & & & 116.4, d & $6.70 \mathrm{~d}(8.5)$ & & \\
\hline $6^{\prime}$ & & & & & 157.2, s & & & \\
\hline $7^{\prime}$ & & & & & 116.4, d & $6.70 \mathrm{~d}(8.5)$ & & \\
\hline $8^{\prime}$ & & & & & 130.6, d & $7.01 \mathrm{~d}(8.5)$ & & \\
\hline
\end{tabular}

${ }^{\text {a }}$ Measured in $\mathrm{CD}_{3} \mathrm{OD},{ }^{\mathrm{b}}$ Measured in $\mathrm{CDCl}_{3}$
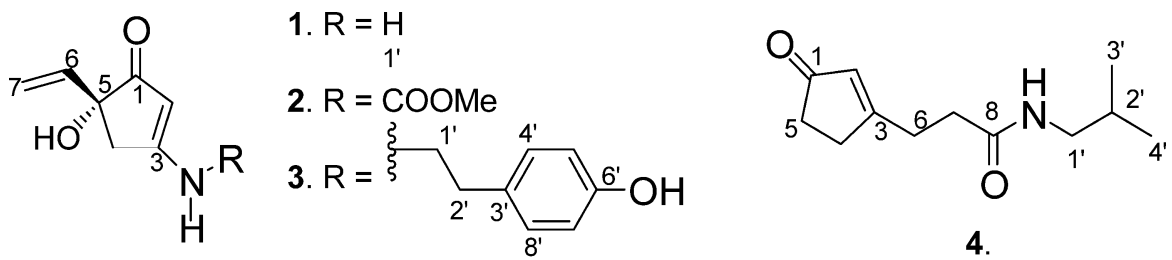

4.

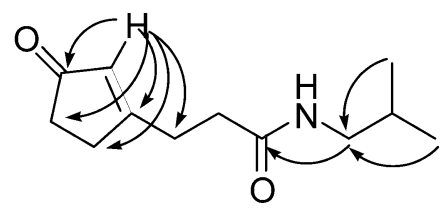

Fig. 1 Main $\mathrm{HMBC}$ correlations of $\mathbf{4}$

from $\mathrm{H}_{3}-3^{\prime}$ and $\mathrm{H}_{3}-4^{\prime}$ to $\mathrm{C}-2^{\prime}\left(\delta_{\mathrm{C}} 28.5, \mathrm{~d}\right)$ and $\mathrm{C}-1^{\prime}\left(\delta_{\mathrm{C}}\right.$ $47.0, \mathrm{t})$ and the methyl carbon of each other. The isobutyl unit was proved to form an amide with carbonyl carbon $\mathrm{C}-8$ $\left(\delta_{\mathrm{C}} 170.9, \mathrm{~s}\right)$ through the HMBC correlation between $\mathrm{H}-1^{\prime}$ and C-8 (Figure 1) and IR absorptions at 1674 and 3294 $\mathrm{nm}$. The structure of $\mathbf{4}$ was thus determined as 3isobutylpropanamide-2-cyclopenten-1-one.

It is interesting to note that the rare 3-amino-5-hydroxy- 5-vinyl-2-cyclopenten-1-one derivatives have previously been isolated from fungi (Trichoderma) $[9,10]$. This is the first time to discover new compounds of the same type from an actinomycete. It was reported that Trichoderma could convert ciprofloxacin and norfloxacin to those conjugates [12]. All the compounds were tested for antibiotic against Bacillus subtilis, Staphylococcus aureus, Escherichia coli, Mycobacterium smegmatis, M. vaccae, 
Penicillium notatum, Phoma destructive, Sporobolomyces salmonicolor, and Candida albicans, and antiviral activity against Coxsackie B3, Influenza A, and Herpes simplex 1, but showed no activity.

\section{Experimental}

\section{Gerneral}

Optical rotations were measured on a DR. KERNCHEN digital automatic polarimeter. IR spectra were recorded on a Bruker IFS 55. NMR spectra were measured on a Bruker Avance dpx 300 (1D) and Bruker Avance drx 500 (2D). ESIMS including HRMS were obtained by triple quadrupole mass spectrometer Quattro (VG Biotech, England).

\section{Streptomyces Strain}

The endophytic Streptomyces sp. (GT-20026114) was isolated from the leaves of mangrove plant Aegiceras comiculatum which was collected from Xia'men, Fujian province of China in August 2002, and incubated on ISP2 medium (artificial sea salt solution $800 \mathrm{ml} /$ liter, malidixic acid $20 \mathrm{mg} /$ liter and cycloheximide $30 \mathrm{mg} /$ liter). Based on morphological and chemotaxonomic characteristics, the strain GT-20026114 can be tentatively assigned to the genus Streptomuces by Hans-Knoell-Institute. The strain was deposited in HKI, Germany.

\section{Culture Conditions}

The spores of GT-20026114 growing on agar slants (ISP2 culture medium) was transferred to a flask $(20 \mathrm{ml})$ and was inoculated on liquid medium GYT (glucose $5 \mathrm{~g} /$ liter, peptone $1 \mathrm{~g} /$ liter, yeast extract $0.5 \mathrm{~g} /$ liter, beef extract $0.5 \mathrm{~g} /$ liter, $\mathrm{NaCl} 3 \mathrm{~g} /$ liter). The flask was incubated at $28^{\circ} \mathrm{C}$ on a rotary shaker for 48 hours, and the mycelium was aseptically transferred to a $500 \mathrm{ml}$ Erlenmeyer flasks containing culture liquid $(200 \mathrm{ml})$. The fermentation culture was then incubated at $28^{\circ} \mathrm{C}$ under shaking condition for 5 days.

\section{Extraction and Isolation}

The fermented supernatant of GT-20026114 (200 liters) was passed through a XAD-161M resin column $\left(20 \times 120 \mathrm{~cm}\right.$ ) by eluting with a gradient $\mathrm{MeOH}-\mathrm{H}_{2} \mathrm{O}$ (from $40: 60$ to $90: 10$ in 38 minutes) to collect seven fractions (FA $\sim$ FG). The fractions were lyophilized, and were screened on TLC (chemical screening) to combine fractions $\mathrm{FE} \sim \mathrm{FG}$, which was desalted by extracting with methanol. The $\mathrm{MeOH}$ extract $(19 \mathrm{~g})$ was subjected to a silica gel column by eluting with $\mathrm{CHCl}_{3}-\mathrm{MeOH}(10: 1)$ to yield 2 (10 mg), 3 (5 mg) and $4(17 \mathrm{mg})$, respectively. The remaining fractions were combined $(2.0 \mathrm{~g})$ and chromatographied on silica gel column $\left(\mathrm{CHCl}_{3}-\mathrm{MeOH}\right.$ $9: 1$ ) firstly, and then purified on Sephadex LH-20 by using $\mathrm{MeOH}$ as an eluting solvent to afford $\mathbf{1}(90 \mathrm{mg})$.

3-Amino-5-hydroxy-5-vinyl-2-cyclopenten-1-one (1), yellowish oil, $[\alpha]_{\mathrm{D}}^{20}+127.1^{\circ}(c 1.54, \mathrm{MeOH})$, UV $\lambda_{\max } \mathrm{nm}$ $(\mathrm{MeOH}): 270$, IR $v_{\max }(\mathrm{KBr}) \mathrm{cm}^{-1}: 3308,3181,2360$, 2340, 1617, 1531, 1418, 1215, 1069, 926. ${ }^{1} \mathrm{H}$ and ${ }^{13} \mathrm{C}$ NMR data, see Table 1. ESIMS $m / z: 140[\mathrm{M}+\mathrm{H}]^{+}, 162$ $[\mathrm{M}+\mathrm{Na}]^{+}$. HRESIMS $\mathrm{m} / \mathrm{z} \quad 162.0540$ (calcd for $\left.\mathrm{C}_{7} \mathrm{H}_{9} \mathrm{NO}_{2} \mathrm{Na}, 162.0531\right)$.

5-Hydroxy-3-[(methoxycarbonyl)amino]-5-vinyl-2cyclopenten-1-one (2), yellowish oil, $[\alpha]_{\mathrm{D}}^{20}+67.6^{\circ}(c) 1.16$, $\mathrm{MeOH})$, UV $\lambda_{\max } \mathrm{nm}(\mathrm{MeOH}): 261$, IR $v_{\max }(\mathrm{KBr}) \mathrm{cm}^{-1}$ : 3710, 3245, 1540, 1522, 1507, 1222, 784. ${ }^{1} \mathrm{H}$ and ${ }^{13} \mathrm{C}$ NMR data, see Table 1. ESIMS $m / z: 198[\mathrm{M}+\mathrm{H}]^{+}$. HRESIMS $m / z 220.0590$ (calcd for $\mathrm{C}_{9} \mathrm{H}_{11} \mathrm{NO}_{4} \mathrm{Na}, 220.0586$ ).

5-Hydroxy-3-[[2-(4-hydroxyphenyl)ethyl]amino]-5vinyl-2-cyclopenten-1-one (3), yellowish oil, $[\alpha]_{\mathrm{D}}^{20}+59.3^{\circ}$ (c 1.73, MeOH), UV $\lambda_{\text {max }} \mathrm{nm}(\mathrm{MeOH}): 232$, IR $\lambda_{\max }(\mathrm{KBr})$ $\mathrm{cm}^{-1}: 3274,1559,1515,1456,1220,774 .{ }^{1} \mathrm{H}$ and ${ }^{13} \mathrm{C}$ NMR data, see Table 1. ESIMS $m / z: 260[\mathrm{M}+\mathrm{H}]^{+}$. HRESIMS $\mathrm{m} / z 260.1279$ (calcd for $\mathrm{C}_{15} \mathrm{H}_{18} \mathrm{NO}_{3}, 260.1287$ ).

3-Isobutylpropanamide-2-cyclopenten-1-one (4), white amorphous powder, UV $\lambda_{\text {max }} \mathrm{nm}(\mathrm{MeOH}) 242$, IR $\lambda_{\max }$ $(\mathrm{KBr}) \mathrm{cm}^{-1}: 3294,2924,1674,1643,1612,1556,1507$, 1224, 849, 778. ${ }^{1} \mathrm{H}$ and ${ }^{13} \mathrm{C}$ NMR data, see Table 1. ESIMS $m / z: 210[\mathrm{M}+\mathrm{H}]^{+}, 232[\mathrm{M}+\mathrm{Na}]^{+}$. HRESIMS $m / z$ : 210.1500 (calcd for $\mathrm{C}_{12} \mathrm{H}_{20} \mathrm{NO}_{2}, 210.1494$ ).

Acknowlegments We are grateful to Dr. F. Gollmick, Dr. A. Berg and colleagues for recording spectral data. This work was funded by the National High-Tech 863 Project (No. 2001AA620403, 2002AA217081), DY105-04-02, and the NSFC (No. 29932030, 30171106), as well as the German Federal Ministry for Education and Research (BMBF; 0312849A and CHN 02/322).

\section{References}

1. Demain AL. Pharmaceutically active secondary metabolites of microorganisms. Appl Microbiol Biot, 52: 455-463 (1999)

2. Behal V. Nontraditional microbial bioactive metabolites. Folia Microbiol 46: 363-370 (2001)

3. Ananda K, Sridhar KR. Diversity of endophytic fungi in the roots of mangrove species on the west coast of India. Can J Microbiol, 48: 871-878 (2002)

4. Jin LH, Lin YC, Yao JH. Two new metabolites from the mangrove endophytic fungus No. 2524. J Asian Nat Prod 
Res 6: 185-191 (2004)

5. Lin $\mathrm{Y}, \mathrm{Wu} \mathrm{X}$, Deng Z. The metabolites of the mangrove fungus Verruculina enalia No. 2606 from a salt lake in the Bahamas. Phytochemistry 59: 469-471 (2002)

6. $\mathrm{Xu}$ Q, Wang J, Huang Y. Metabolites from mangrove endophytic fungus Dothiorella sp. Acta Oceanol Sinica 23: 541-547 (2004)

7. Ismet A, Vikineswary S, Paramaswari S. Production and chemical characterization of antifungal metabolites from Micromonospora sp. M39 isolated from mangrove rhizosphere soil. World J Microbiol Biot 20: 523-528 (2004)

8. $\mathrm{Xu} \mathrm{M,} \mathrm{Deng} \mathrm{Z,} \mathrm{Li} \mathrm{M,} \mathrm{Li} \mathrm{J,} \mathrm{Fu} \mathrm{H,} \mathrm{Proksch} \mathrm{P,} \mathrm{Lin} \mathrm{W.}$ Chemical constituents from the mangrove plant, Aegiceras corniculatum. J Nat Prod 67, 762-766 (2004)
9. Triptikumar M, Kirity R, Sawant SN. On an unstable antifungal metabolite from Trichoderma koningii. Isolation and structure elucidation of a new cyclopentenone derivative (3-dimethylamino-5-hydroxy-5-vinyl-2-cyclopenten-1-one). J Antibiot 49: 210-211 (1996)

10. Strunz GM, Ren WY, Stillwell MA, Valenta Z. Structure and synthesis of a new cyclopentenone derivative from Trichoderma album. Can J Chem 55: 2610-2612 (1977)

11. Kuo RY, Chen CY, Lin AS. A new phenanthrene alkaloid, romucosine I. from Rollinia mucosa Baill. Z Naturforsch B: Chemical Science 59: 334-336 (2004)

12. Parshikov IA, Moody JD, Freeman JP, Lay JO Jr, Williams AJ, Hcinze TM, Sutherland JB. Formation of conjugates from ciprofloxacin and norfloxacin in cultures of Trichoderma viride. Mycologia 94: 1-5 (2002) 